\title{
Analysis of a Special, 3D Metal-Printed HPDC Tool Material
}

\author{
S. E. KOVÁCS ${ }^{1}$, L. VARGA ${ }^{2}$, Zs. SZENTES ${ }^{3}$ \\ ${ }^{1}$ University of Miskolc, Faculty of Material Science and Engineering, Institute of Metallurgical and Foundry \\ Engineering, kovacssandorendre@gmail.com \\ ${ }^{2}$ University of Miskolc, Faculty of Material Science and Engineering, Institute of Metallurgical and Foundry \\ Engineering, laszlo.varga.mak@gmail.com \\ 3Foundry Solid Kft, szentes.zsolt@foundry-solid.com
}

Abstract.High Pressure Die Casting (HPDC) is still the most productive metal-casting method of our time, however the more demanding are the industrial expectations, the more challenging it becomes to ensure the creation of the difficult cavity geometries and the thermal balance of the die-cast tool. New perspective is required, thus we can utilize high heat-conductivity tool steels and additive manufacturing technology.

Keywords: 3D printing, HPDC, tool steel, special alloy, simulation, mechanical testing

\section{Introduction}

The conformal cooling channels for High Pressure Die Casting (HPDC) technology, is an alternative method, which enables a constant distance between the cooling channel and the casting. In contrast to the conventional method, where these cavities are made by linear drilling, it can consist of non-linear sections, or even spirals as well. Linear cavities are not always able to remove as much heat as the process requires, thus the heat-equilibrium of the surface will become uneven. This equilibrium can be sustained by using the conformal cooling, because it can dissipate the heat evenly from across the whole surface. This balanced heat distribution will cause less internal stress in the die and also improves the quality of the product [1]. Fig. 1 shows a comparison between a conventional, and a conformal cooling channel.
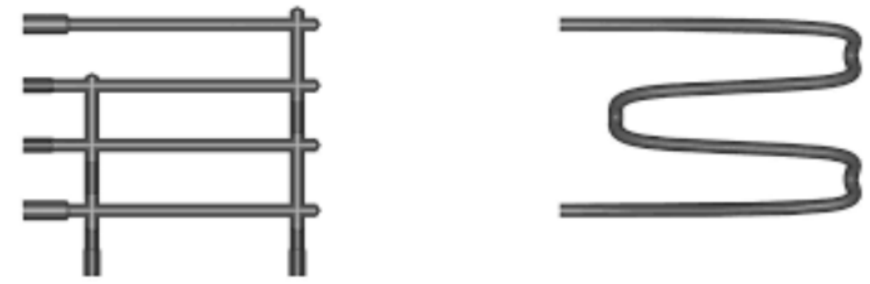

Figure 1. Conventional (left) and conformal (right) cooling channels [2]

However, thermophysical parameters of HPDC die materials are not only influenced by the cooling channels. Choosing the right tool material also has a great impact on the thermal balance. The effect of 
these two designs has an important role in the lifetime of the tool, thus choosing the right material and high-end optimization of the cooling channels will ensure a consistent and stable manufacturing process. [3]

During our work, we created a model environment with a computer simulation software to test out different material and cooling channel settings, and their actual effect on the thermal balance of the HPDC machine. Additionally, we made mechanical measurements towards different attributes of the high heat-conductivity tool steel which involved hardness testing, Charpy-test and tensile strength analysis. These physical attributes were also compared with their respective values of a conventionally used tool steel.

\section{3D printed, conformal cooling channel}

3D printing produces an increasing amount of tool products, arming both polymer and metal manufacturing machines with different parts. These machines are operating in serial production, thus highly required for these tool materials to be able to withstand a long-term production period. The introduction of the 3D printed tool parts was centered around the principle of rapid tooling. Rapid tooling can lower the ready time of these parts, thus eliminating both waiting time and transportation expenses. Utilization of these 3D printed parts made it more and more clear, that 3D printing can not only achieve this previous statement, but the parts made by it have also a good influence on the process as a whole and the quality of the manufactured product. [4]

Cooling time can be reduced up to $25 \%$. This effect becomes ever more perceptible as the product geometry becomes more difficult. The complexity of the product will declare the sufficient heat dissipation. As the complexity increases, it is gradually harder to maintain the thermal balance during the process. An actual conformal cooling channel is being represented in Fig. 2 [1].

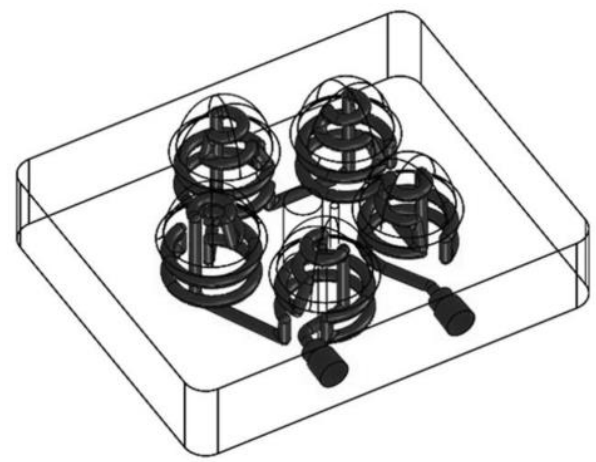

Fig. 2. Conformal cooling channel used in an industrial environment [5]

\section{Setup of the Computer simulation experiments}

As a base comparison for these simulation experiments, we defined two particular tool steel alloys with different heat conductivity properties. A Dievar-type-alloy became the reference material, while we conducted measurements on an HTCS130 code-named alloy. This HTCS130 alloy has exceptional heat conductivity properties. 
The goal of this comparison was to test these two different alloys with different types of cooling channels. To do so, we created a simulation order, which is presented in Table I.

\begin{tabular}{|c||c|c|}
\hline \multicolumn{1}{|c||}{} & Tool material & Cooling channel \\
\hline \hline$" A "$ & Dievar & linear / conventional \\
\hline${ }^{\prime \prime}$ & Dievar & conformal \\
\hline "C $C$ " & HTCS130 & linear / conventional \\
\hline${ }^{\prime \prime}$ & HTCS130 & conformal \\
\hline
\end{tabular}

Table I. Dievar and HTCS130 simulation order

The numerical values of both alloy's heat conductivity is presented in Table II.

\begin{tabular}{|c||c|c|}
\hline $\begin{array}{c}\text { Temperature, } \\
{ }^{\circ} \mathrm{C}\end{array}$ & $\begin{array}{c}\text { Heat conductivity value (Dievar), } \\
\mathrm{W} / \mathrm{m} /{ }^{\circ} \mathrm{C}\end{array}$ & $\begin{array}{c}\text { Heat conductivity value (HTCS130), } \\
\mathrm{W} / \mathrm{m} /{ }^{\circ} \mathrm{C}\end{array}$ \\
\hline 20 & 29.00 & 60.00 \\
\hline 400 & 31.00 & 60.00 \\
\hline 600 & 32.00 & 60.00 \\
\hline 1000 & 32.50 & 60.00 \\
\hline
\end{tabular}

Table II. Heat conductivity values of both Dievar and HTCS130

The geometry used for these simulations was a knobby plate, which provided us a relatively simple geometry with many different protrusions. The geometry is shown in Fig. 3.

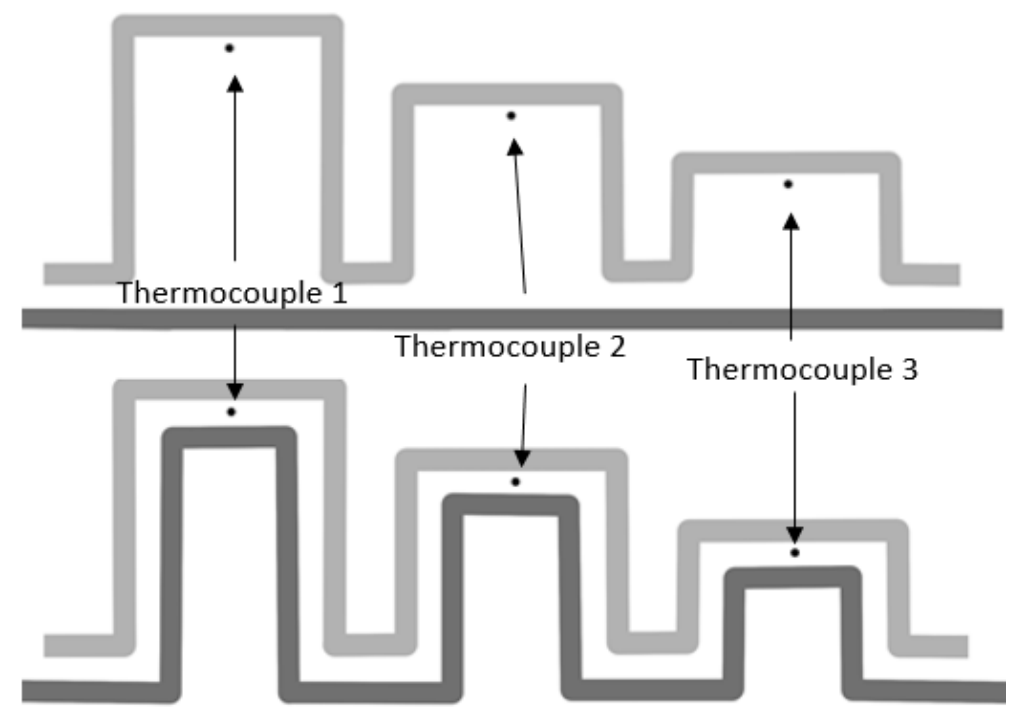

Fig. 3. Geometries used for model simulations

This geometry was exceptionally useful, because of its simplicity and thin walled structure, also each protrusion is present in different height, thus enabling a cooling system for measuring extreme values.

The essence of this measurement was that the thermocouples had constant locations. The selected plain was d via the simulations software, and so the thermocouples were placed on the centerline of the geometry.

Table III. shows the input parameters of this simulation. To achieve the sufficient interpretability, in regards to the cooling channels, extreme designs were created. 
International Journal of Engineering and Management Sciences (IJEMS) Vol. 5. (2020). No. 2

DOI: 10.21791/IJEMS.2020.2.30.

\begin{tabular}{|c|c|c|}
\hline & Dievar & HTCS130 \\
\hline Cast material & EN AC 46000 & EN AC 46000 \\
\hline Melt temperature & $690^{\circ} \mathrm{C}$ & $690^{\circ} \mathrm{C}$ \\
\hline Mould temperature & $180^{\circ} \mathrm{C}$ & $180^{\circ} \mathrm{C}$ \\
\hline $\begin{array}{l}\text { Minimal distance of the } \\
\text { cooling channel from the } \\
\text { casting }\end{array}$ & $5 \mathrm{~mm}$ & $5 \mathrm{~mm}$ \\
\hline $\begin{array}{l}\text { Maximum distance of the } \\
\text { cooling channel from the } \\
\text { casting }\end{array}$ & $60 \mathrm{~mm}$ & $5 \mathrm{~mm}$ \\
\hline Coolant & water & water \\
\hline Coolant pressure & $1 \mathrm{bar}$ & 1 bar \\
\hline Coolant temperature & $80^{\circ} \mathrm{C}$ & $80^{\circ} \mathrm{C}$ \\
\hline Coolant flow rate & $0.1 \mathrm{~L} / \mathrm{s}$ & $0.1 \mathrm{~L} / \mathrm{s}$ \\
\hline
\end{tabular}

Table III. Input parameters of the model simulation

Table IV. shows different cycle times. At the beginning of our measurements, a longer cycle period was utilized.

\begin{tabular}{|l||l|l|}
\hline \multicolumn{1}{|c|}{} & "A" measurement & „B" measurement \\
\hline Die closed & $12 \mathrm{~s}$ & $8 \mathrm{~s}$ \\
\hline Air cooling & $5 \mathrm{~s}$ & $2 \mathrm{~s}$ \\
\hline Water spraying & $8 \mathrm{~s}$ & $5 \mathrm{~s}$ \\
\hline Air cooling & $5 \mathrm{~s}$ & $2 \mathrm{~s}$ \\
\hline Whole cycle & $30 \mathrm{~s}$ & $17 \mathrm{~s}$ \\
\hline
\end{tabular}

Table IV. Cycle times of the model simulation

The " $\mathrm{A}$ " measurement table had been abandoned for the reason it could not process the geometry conditions sufficiently, thus the calculations were set off. These time parameters were somewhat longer than it was intended for a geometry this small, so we had to lower these values. Measurement "B" table shows these modified time periods. This modification could avert the occurring simulation error.

\subsection{Computer simulation results}

The computer simulation measurement was carried out with the sole purpose of showing the difference in utilizing different heat-conductivity material and cooling design. The geometries were presented in Fig. 3, and their respective setups in Table I. The reference value became the " $\mathrm{A}$ " member of the table, because this can be regarded as the most commonly used design. The evaluation results for Dievar alloy are represented in Fig. 4, and for HTCS130 Fig. 5. 


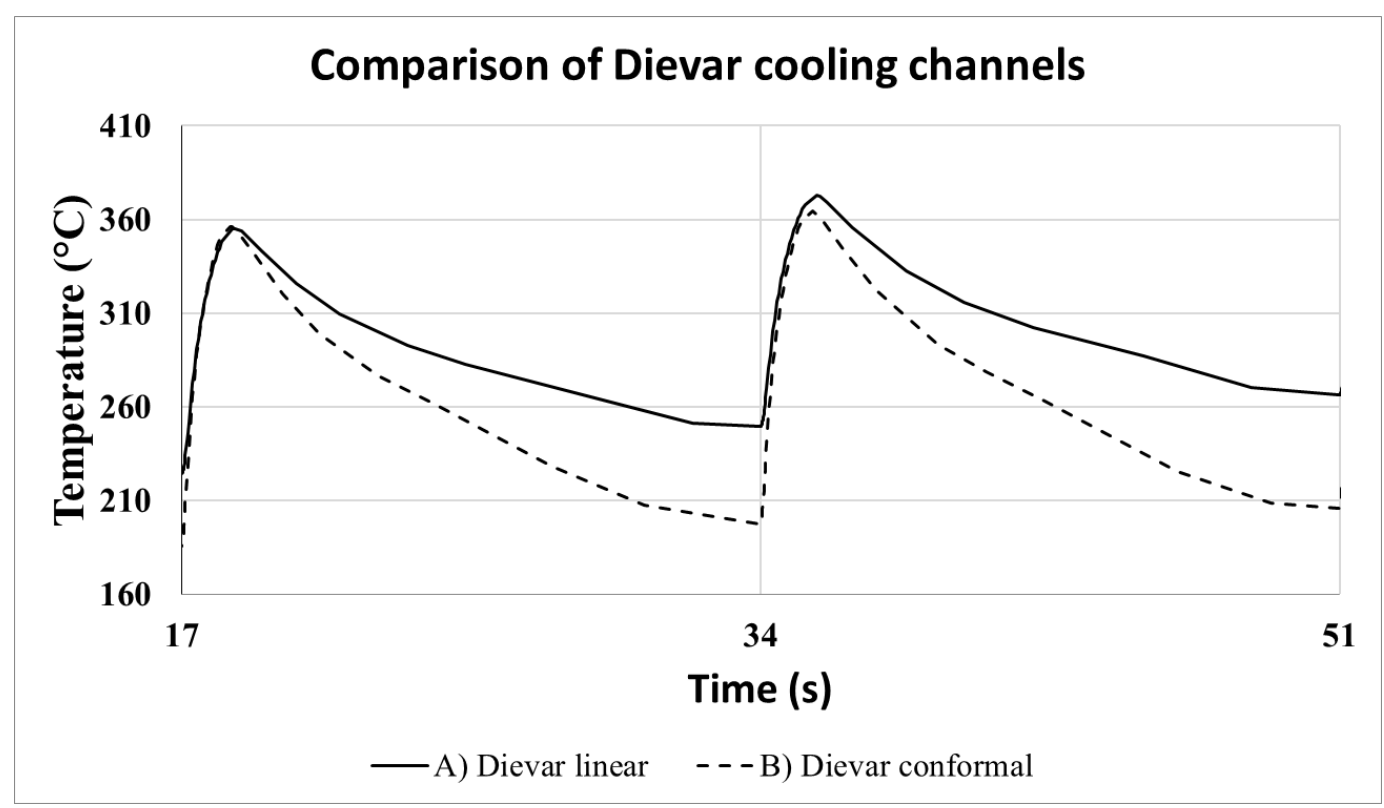

Fig. 4. Dievar alloy with linear (A) and conformal (B) cooling channel designs

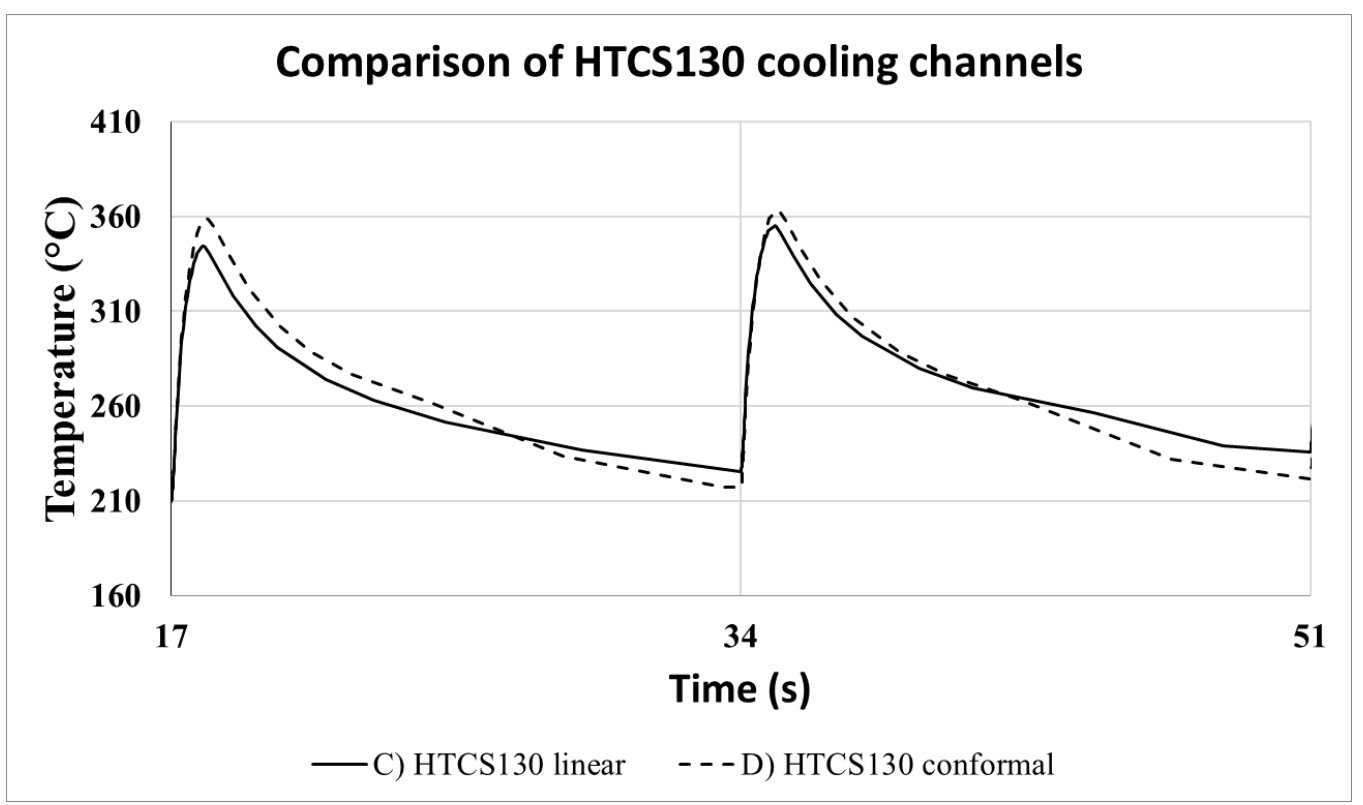

Fig. 5. HTCS130 alloy with linear (C) and conformal (D) cooling channel designs

Fig. 4 and 5 show that the heat balance changes with each modification. This results in a continuously changing system, where each factor has great influence on the thermal equilibrium. The values are showing steady improvement from " $A$ " to " $D$ ", however. It is very important to take a closer look at the "B" and "C" designs. Here, we can notice a slight resemblance. At step "B" we can observe that the effect of the conformal cooling channel regarding its linear pair is drastic, however taking a look at step " $\mathrm{C}$ " it can be said that utilizing a high heat conductivity tool material can almost approach this tremendous effect even with linear cooling design. Before deploying any of the measured designs, one must always take it into consideration what it is that the current process needs the most. 


\subsection{Simulations of an industrial HPDC tool core}

The next step in our project was to analyze an already deployed HPDC tool core, with a conventional cooling channel built-in. In this case, the geometry was given, thus the main question of this comparison was only the thermophysical values of the different tool alloys. A conceptual illustration of this measurement is demonstrated in Fig. 6.

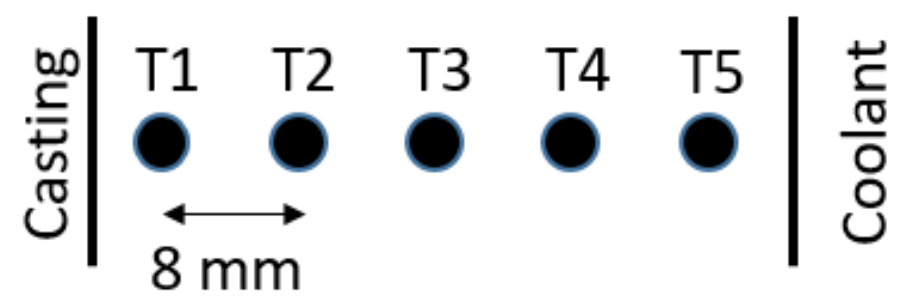

Fig. 6. Thermocouples placed in the measured HPDC tool core

The construction of this industrial simulation was a lot more difficult, than our previous model, thus required a more complex approach. Table $\mathrm{V}$ shows the setup difference between the model and the industrial simulation.

\begin{tabular}{|c|c|c|}
\hline & Model simulation & Industrial simulation \\
\hline \hline Deployed thermocouples & 3 & 5 \\
\hline Position of the thermocouples & $\begin{array}{c}\text { evenly distanced from the } \\
\text { casting and cooling channel }\end{array}$ & $\begin{array}{c}\text { every } 8 \mathrm{~mm} \text { from casting to } \\
\text { the cooling channel }\end{array}$ \\
\hline Coolant & water & water \\
\hline Coolant pressure & $1 \mathrm{bar}$ & $1 \mathrm{bar}$ \\
\hline Coolant temperature & $80^{\circ} \mathrm{C}$ & $80^{\circ} \mathrm{C}$ \\
\hline Coolant flow rate & $0.1 \mathrm{~L} / \mathrm{s}$ & $0.1 \mathrm{~L} / \mathrm{s}$ \\
\hline
\end{tabular}

Table V. Comparison of the model and industrial simulations

Fig. 7 represents the heat flow differences during the process. These heat flow values are calculated values, based on the temperature results taken from each deployed thermocouples.

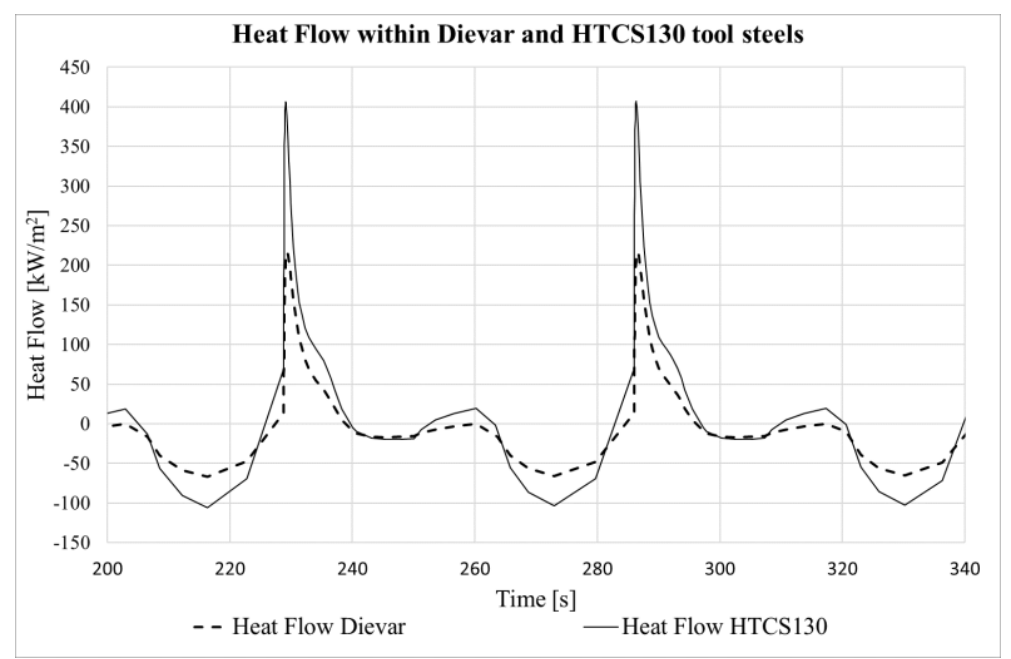

Fig. 7. Heat flow differences between Dievar and HTCS130 alloys 
As Fig. 7 shows, utilizing a higher heat conductivity alloy will lead to a more stable temperature distribution during the HPDC cycles.

The more stable this heat attribute, the lifetime of the HPDC machine will increase, the surface will suffer less intense heat shock, due to the lesser thermal gradient.

\section{3D printing, the additive manufacturing technology}

3D printing is an additive manufacturing process. The name was chosen by the ASTM F42 commission, which totally distances it from those manufacturing technologies where the product is created by material extraction. In this case, the final product is being built by material addition, layer by layer. Geometries can be built using different layer thicknesses, and this attribute will have a tremendous effect on the printing process. Fig 8 represents a geometry built using different layer thicknesses.

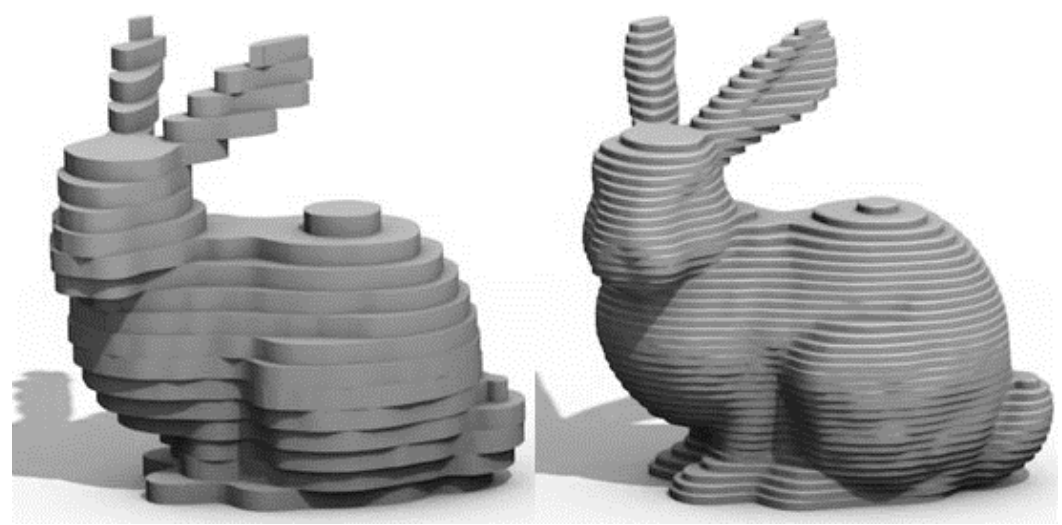

Fig. 8. Thicker (left) and thinner (right) layer systems [7]

Utilizing different layer thicknesses will lead to various surface qualities. These layers for a printed product can differ from 20 to $100 \mu \mathrm{m}$, so the user can decide the printing resolution. This resolution is strongly related to the surface quality and the actual printing time. Using thicker layers might cut the process time in half, however it will result in a coarse geometry [6]. The more complex the model is; the thinner layers are recommended.

Since the 3D printing can make extremely complex geometries, post-processes are not always necessary during production. Moreover, post-processes only add more expenses to an already expensive manufacturing method, which lowers the total value. A well designed geometry can save time and resources, both of them can be crucial factors. To complete a printing process within a reasonable time, one must always design the characteristics focusing on the product.

\subsection{Printability}

Without sufficient printing parameters this process will most likely cause higher residual stress than intended. This stress will add up during the layer by layer production, and at a certain point will initiate deformation or cracks. These errors in the product can occur anytime, there is a possibility for it even during production. 
At the moment, there are two kinds of printable alloys. One type of alloys is particularly sensitive for the printing parameters, and the other which is not. The ones which are not sensitive can be considered as materials with a universal printability attribute. This attribute enables the alloy to be printed with different 3D printers, without changing the initial printing settings. Those which are sensitive are considered unprintable, or circumstantial alloys because many printing settings must be changed from the bed temperature up to the laser performance to accomplish a successful process [3]. 3D printing of the HTCS130 alloy was a test procedure, here the alloy was printed with minimal changes in the basic settings. The reference alloy, the Dievar, however, cannot be printed, thus experiments were not carried out regarding this area, it is only present for the sake of comparison. Those metal alloys are suitable for 3D printing processes, such as DMLS, which can be welded. Fig 9 shows the construction system of a DMLS process.

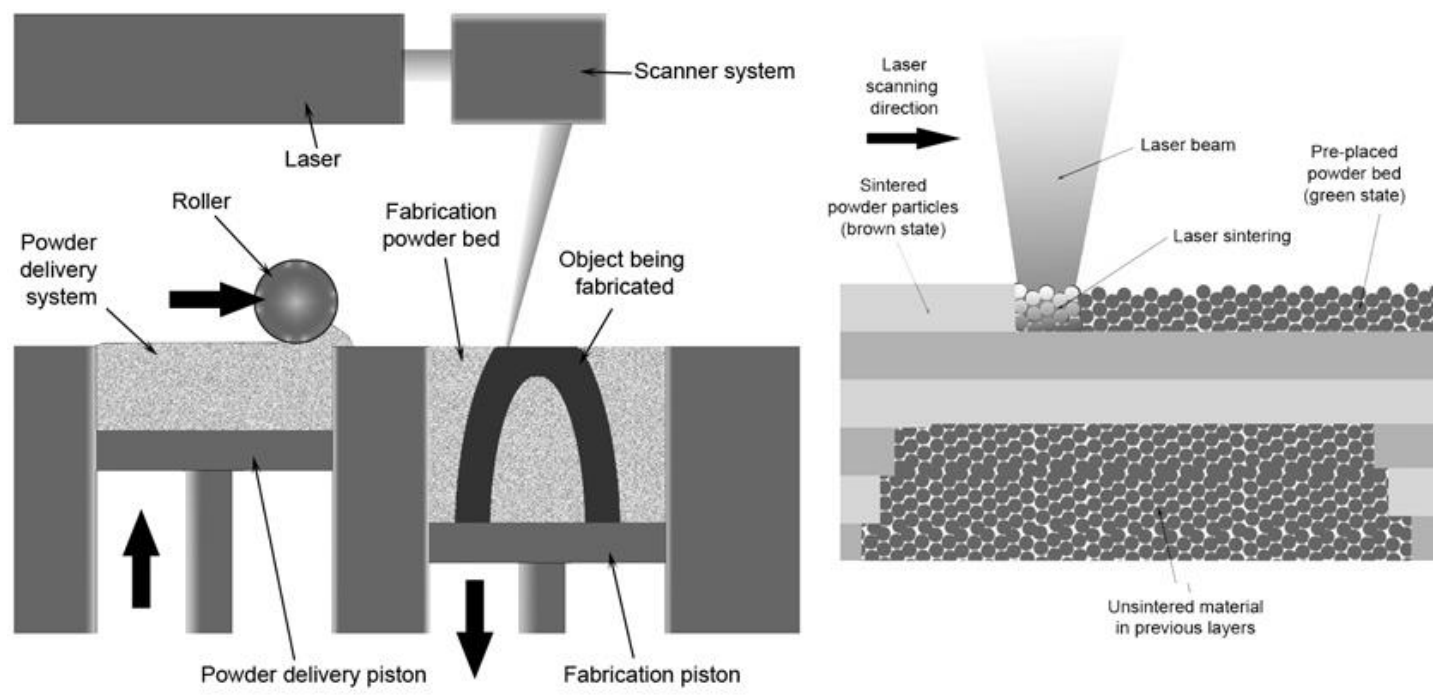

Fig. 9. Powder based 3D printing system [8]

During the process, as an effect of the laser performance, the chemical composition of the printed material might change. This change can be traced back to the occurring high local temperatures. This burning out phenomenon is highly important, because when the user is choosing a particular alloy for printing, he wants the target product to wield the same chemical composition as the selected powder. Another important factor is the resemblance to the CAD file. A lot of stress can build up within the material during 3D printing, and the effect of this built-up stress can cause the geometry to warp. When the geometry warps, the outline and the layer structure will lose its resemblance to the CAD file. This can occur if not sufficient or overpowered laser beam performance is used. When the laser is too powerful for the printed material it might melt more layers then intended, and this re-melting and resolidifying will cause geometrical errors. [3]

The printing process of the HTCS130 alloy was carried out utilizing a $175 \mathrm{~W}$ laser performance with $20 \mu \mathrm{m}$ layer thickness. 


\section{Laboratory measurements}

The next part of our work was the analysis of mechanical parameters. To do so we made various test samples, for each respective analysis method. Moreover, we made scanning electron microscopy (SEM) on the powder and also on the test samples. The following measurements were carried out:

- HTCS130 test piece made by a conventional method

$\circ$ texture analysis

$\circ$ texture analysis of the heat-treated specimen

- Powder

- granulometrical analysis (SEM)

- 3D printed trial piece

$\circ$ texture analysis

○ hardness test

- 3D printed technological test samples

$\circ$ texture analysis

○ non-destructive residual stress measurement

o Charpy-test

○ hardness test

$\circ$ heat treatment

$\circ$ texture analysis of the heat-treated specimen

\subsection{HTCS130 rod made by conventional methods}

We received a test piece made by a conventional manufacturing method from the HTCS130 alloy, which became the reference material for the measurements conducted on the 3D printed specimens. The texture of this test piece is being shown in Fig. 10.

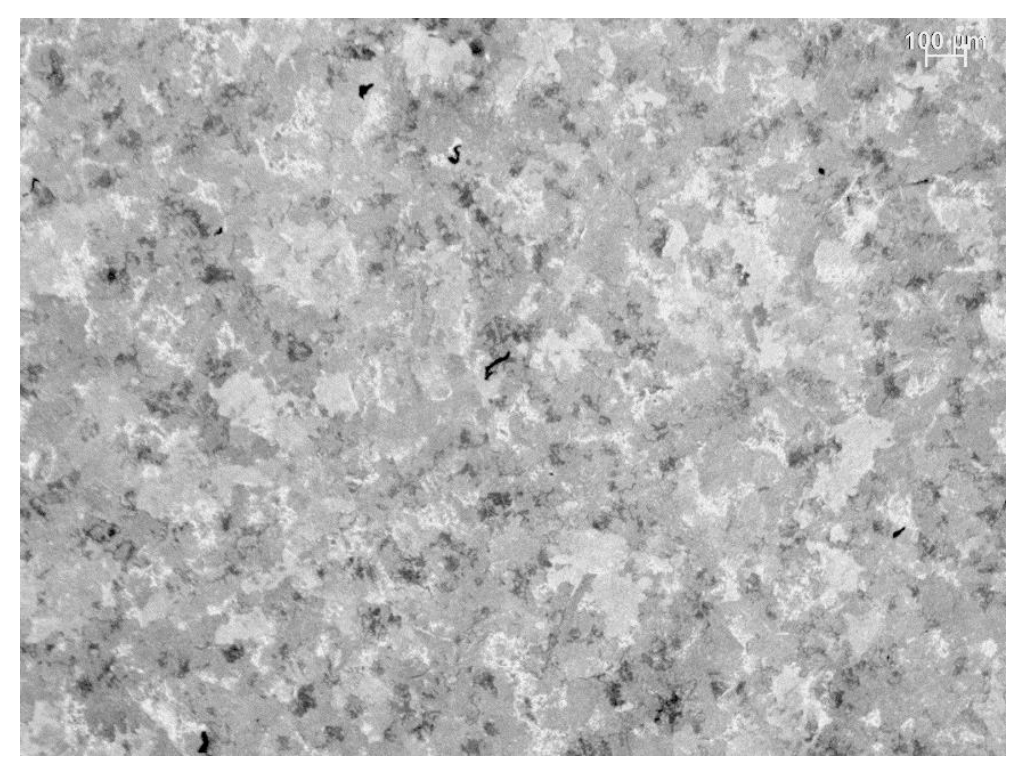

Fig. 10. Texture of the conventionally made HTCS130 alloy

According to the datasheet, this alloy has exceptional purity and homogenous structure moreover, has a great heat-conductivity attribute and superior mechanical properties compared to other high-heat 
conductivity tool steels. The combination of all these proves the alloy to be more than sufficient for HPDC deployment. The actual values are presented in Table VI.

\begin{tabular}{|c|c|}
\hline & Datasheet values \\
\hline Rockwell hardness & $34-52$ \\
\hline Charpy & $28,5 \mathrm{~J}$ (room temperature) \\
\hline 0,2\% Yield Strength & $1328 \mathrm{MPa}$ \\
\hline Tensile Strength & $1343 \mathrm{MPa}$ \\
\hline Table VI. Mechanical datasheet values of HTCS130
\end{tabular}

This section will involve the analysis of all these mechanical properties, breaking it down to different levels of comparison. Beyond these steps, as the start of our investigations, we made measurements towards the granulometrical properties of the metal powder itself.

\subsection{Scanning electron microscopy of the alloy powder}

The goal of the SEM analysis was to get an insight into the powder structure, how spherical are the different powder particles, what is their size, distribution, average diameter and so on. Fig 11. shows a section of this investigated powder.

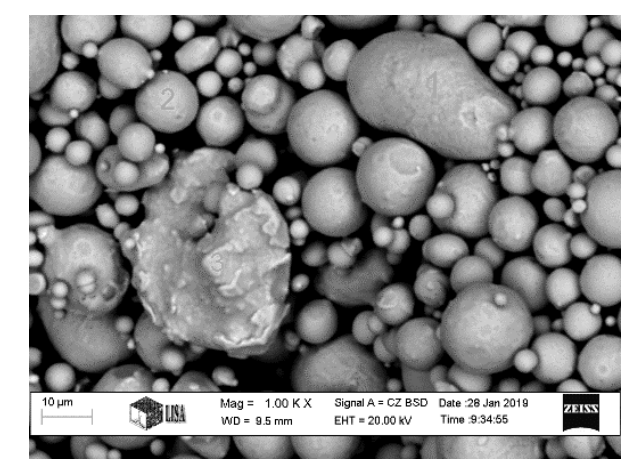

Fig. 11. Powder alloy particle distribution at 1000x zoom value

Not all the particles took a spherical morphology. There are crumbled and coarser particles as well as really small segments. Diving deeper into the composition analysis, we looked into the chemical composition of these deformed particles. This analysis showed no difference between the spherical and non-spherical structures. However, the shape of these grains somehow have an influence on the 3D printing process as a whole.

The analyzed powder proved to be sufficient for the process due to its average diameter of $19 \mu \mathrm{m}$ and a specific surface area of $913 \mathrm{~cm}^{2} / \mathrm{g}$.

\subsection{Non-destructive residual stress analysis of the 3D printed test specimens}

Residual stress is present in every crystalline-structured material. It is an inner stress state, which occurs especially during a layer-by-layer manufacturing process like 3D printing. It might influence the printability of some geometries, and its value can be traced back to particular printing methods. 
Our analysis included a non-destructive type residual stress analysis carried out on Charpy test pieces. These samples were especially good for this measurement due to their bulky structure. The measured values are shown in Table VII.

\begin{tabular}{|l||l|l|}
\hline & $\boldsymbol{\sigma}$ (MPa): $\mathbf{0 . 0}^{\circ}$ & $\mathbf{( \pm )}$ \\
\hline $1-{ }^{\circ} A^{\prime \prime}$ & -115.6 & 9.1 \\
\hline $1-{ }^{\prime} B^{\prime \prime}$ & 237.5 & 60.3 \\
\hline $1-{ }^{\prime \prime} C^{\prime \prime}$ & 398.4 & 21.7 \\
\hline $2-{ }^{\prime \prime}$ & 81.2 & 36.8 \\
\hline $2-{ }^{\prime \prime} B^{\prime \prime}$ & 64.1 & 45.1 \\
\hline $2-{ }^{\prime \prime}$ & 233.8 & 54.4 \\
\hline
\end{tabular}

Table VII. Residual stress occurring in Charpy test pieces

There is a great difference between the two test pieces. This is due to a printing error, where the support structure has broken during production, and letting the product to warp according to the occurring residual stresses. Also we can observe that the smallest amount of residual stress is present in the middle of the body. This happened due to the lost connection with its support structure, the volume simply could not hold against the built-up residual stress.

Table VII also shows, that there is a huge residual stress difference between each end of this printed bulk. Taking a look at the first measured test specimen, we can notice that there is a $-115.6 \mathrm{MPa}$ stress value at one end, and almost $400 \mathrm{MPa}$ on the other. This huge difference can be traced back to the printing orientation. The stress distribution will change every time the actual geometry is being printed out in a different orientation.

\subsection{Mechanical properties of the 3D printed technological test specimens}

The Charpy-test was carried out according to the MSZ EN 10045-1 "Charpy testing of metals" Hungarian standard, on a Charpy-style pendulum-percussion machine, with a $30 \mathrm{~kg}$ hammer, at room temperature.

The results are the following:

- $\quad$ Test specimen I.: $2.8 \mathrm{kpm} \rightarrow 27.46 \mathrm{~J}$

- Test specimen II.: $2.9 \mathrm{kpm} \rightarrow 28.44 \mathrm{~J}$

These results are exceeding the Dievar alloy's results at room temperature, which is 17-19 J, also matches with the given HTCS130 datasheet values which is 28.5J.

For the hardness tests, we conducted Rockwell-hardness measurements, which also had a resemblance with the given datasheet values:

- $\quad$ Test specimen I.:
o HRC: 45
O HRC: 44
o HRC: 38 
International Journal of Engineering and Management Sciences (IJEMS) Vol. 5. (2020). No. 2

DOI: 10.21791/IJEMS.2020.2.30.

- $\quad$ Test specimen II.:

○ HRC: 41

○ HRC: 44

○ HRC: 40

The Rockwell hardness of the HTCS130 in the datasheet is HRC: 34-52, thus the 3D printing manufactured pieces are sufficient to the standards, also matching the hardness values of the Dievar at room temperature, which is HRC: 44.

We made measurements towards the tensile strength parameters of these 3D printed test pieces, these measured values are being presented in Table VIII.

\begin{tabular}{|l|l|l|}
\hline Specimen number & $\mathbf{0 , 2 \%}$ Yield Strength [MPa] & Maximum tensile strength [MPa] \\
\hline 1 & 1214 & 1422 \\
2 & 1201 & 1412 \\
3 & 1204 & 1418 \\
\hline
\end{tabular}

Table VIII. Tensile strength analysis results

The datasheet values of this measurement are $1328 \mathrm{MPa}$ for yield strength and $1343 \mathrm{MPa}$ for tensile strength. Comparing the results, we can say that the tensile strength measurements for the 3D printed specimens made far better results than the conventionally made pieces.

\subsection{Texture comparison of a Casting and 3D printed test piece}

Texture analysis was carried out according to the following preparation method:

- grinding, with grinding paper
- 220
○ 320
$\circ 500$
$\circ 800$

- polishing

- 3 micron

- etching

$\circ$ nital, 5 second

Afterwards, we made a comparison of the two manufacturing types, which is presented in Fig. 12.

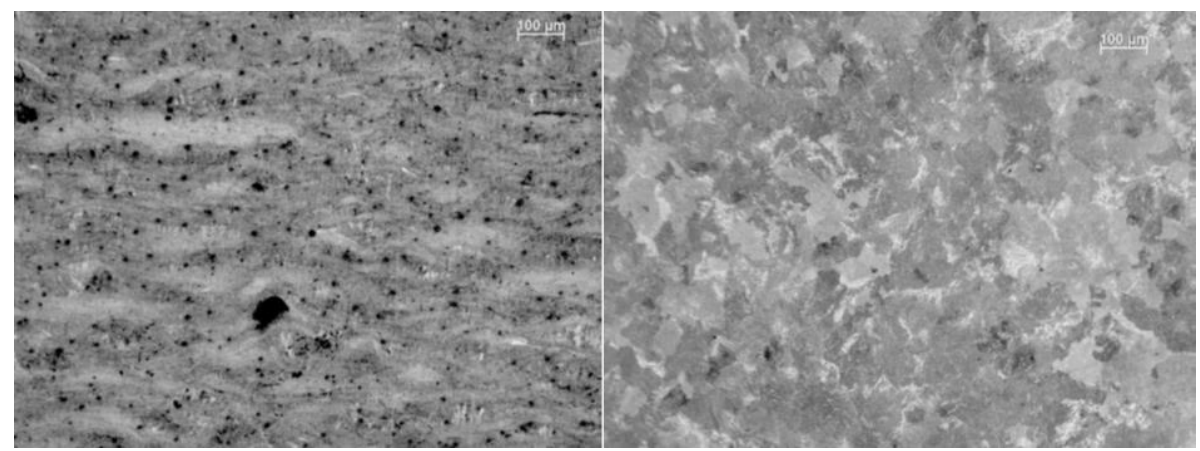

Fig. 12. Texture analysis of a 3D printed part (left) and a conventionally made part (right) 
The structure of the 3D printed specimen shows a unique texture. Each black point on the record is a pore, also we can notice the remnants of layers left behind by the DMLS technology. These pores are showing a homogenous dispersion, and their presence had no negative effect towards the utilization requirements.

\subsection{Heat treatment of the 3D printed test specimen}

As a closure of our work, we conducted heat treatments on both 3D printed and conventional specimens. The heat treatment was carried out at $1050^{\circ} \mathrm{C}$ and it lasted one hour. After treatment, we let the specimens cool down on air. The preparation of the heat-treated specimen was followed the method given in 5.5, and Fig. 13 shows the comparison of the 3D printed specimens pre- and post-heat treatment.

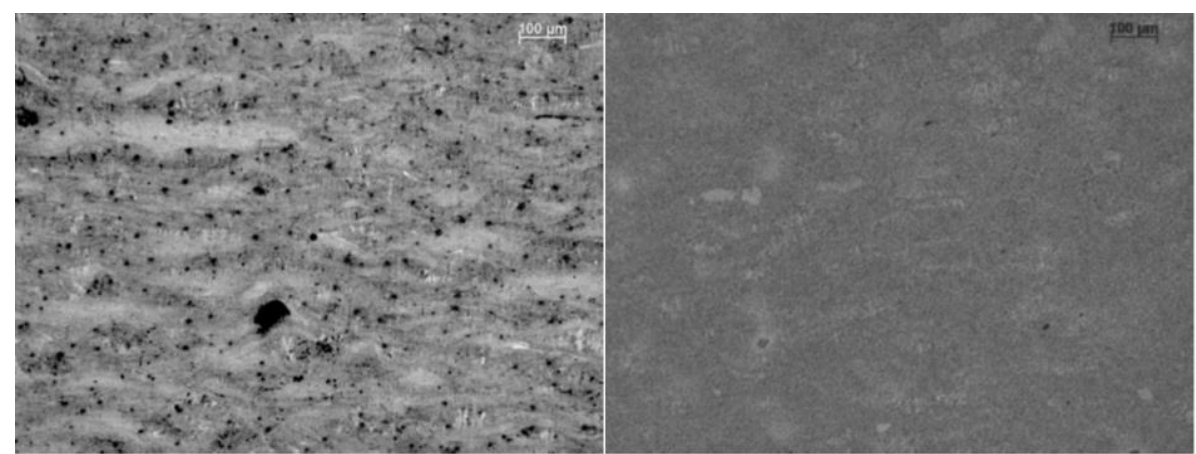

Fig. 13. Texture analysis of a 3D printed test specimen pre-(left) and post-(right) heat treament

The microstructural image of the heat treated piece, shows that, the pores have changed their location in the volume. This phenomenon can be traced back to the residual stresses. This stress made the already softened material to change shape, and so the heat treatment catalyzed a migration in the material. These pores have opened up with the surface, or they have united as a bigger pore volume.

\section{Summary}

After conducting all the listed measurements, it is stated that the conformal cooling channel, and the high heat-conductivity tool steel are both significantly improve the heat distribution of an HPDC process. Model simulation results are showing that steadily improving the attributes, by utilizing conformal cooling channels and high heat conductivity tool steel, the cyclic workload drastically decreases. An order can be made from the four measured values:

1. Conformal cooling with HTCS130

2. Linear cooling with HTCS130

3. Conformal cooling with Dievar

4. Linear cooling with Dievar

However not always the best is the most economical. Taking a look at the results of the model simulation, there is no significant difference between the first and second one. Also, the second and third one shows a great resemblance. Utilizing different designs depends on the actual need of the process. 
The following measurements were carried out towards the mechanical and thermophysical properties of the HTCS130 created by 3D printing. These mechanical values are shown in Table IX.

\begin{tabular}{|l||ll|}
\hline & Measured values & Datasheet values \\
\hline \hline Trial printing, $H R C$ & $45 / 46 / 44$ & $34-52$ \\
\hline Charpy 1 HRC & $45 / 44 / 38$ & $34-52$ \\
\hline Charpy 2 HRC & $41 / 44 / 40$ & $34-52$ \\
\hline Charpy test -1 & $27.46 \mathrm{~J}$ & $28.5 \mathrm{~J}$ (room temperature) \\
\hline Charpy test -2 & $28.44 \mathrm{~J}$ & $28.5 \mathrm{~J}$ (room temperature) \\
\hline $0.2 \%$ Yield Strength & $1214 / 1201 / 1204(\mathrm{MPa})$ & $1328 \mathrm{MPa}$ \\
\hline Tensile strength & $1422 / 1412 / 1418(\mathrm{MPa})$ & $1343 \mathrm{MPa}$ \\
\hline
\end{tabular}

Table IX. Comparison of all conducted mechanical properties

- First of all, the heat-flow measurement demonstrated, that the HTCS130 tool steel has superior heat conductivity to the Dievar counterpart.

- The hardness values of the 3D printed HTCS130 matched the datasheet values

- Charpy test results also matched the datasheet, and the Dievar as well

- Heat treatment of both conventional and 3D printed test pieces made the texture more homogenous, this has a great effect on the porosity structure in the volume

- Residual stresses had a great difference at each end of the volume, this difference can be traced back to the printing orientation.

- The tensile strength values of the 3D printed specimens exceeded the conventionally made counterparts.

- The granulometry of the metal powder was sufficient for the 3D printing process

Additional measurements can involve:

- Mechanical analysis at a higher temperature for both Dievar and HTCS130 alloys

- Comparing the HTCS130 with other tool steels

- 3D printing of lesser heat-conductivity materials

- More complex model simulation setup

- More complex conventional cooling setup

- Effect of the coarse powder particles on the 3D printing process

\section{Acknowledgements}

The described work was carried out as part of a project supported by the Foundry Solid Kft. The 3D printed test specimens were made in the Széchényi István University, Győr, Hungary, and the measurements were carried out at the University of Miskolc.

\section{Reference}

[1] Zink Béla, Szabó Ferenc, Hatos István. Hargitai Hajnalka és Kovács József Gábor (2014) DMLS szerszámbetétek szimulációs vizsgálata. MÛANYAG- ÉS GUMIIPARI ÉVKÖNYV, 12 (1). pp. 80-87. ISSN 1589-6269

[2] https://aip.scitation.org/doi/abs/10.1063/1.5008200?journalCode=apc 
International Journal of Engineering and Management Sciences (IJEMS) Vol. 5. (2020). No. 2

DOI: 10.21791/IJEMS.2020.2.30.

[3] T. Mukherjee, J.S. Zuback, A. De \& T. DebRoy - Printability of alloys for additive manufacturing

[4] Antonio Armillotta, Raffaello Baraggi, SLM tooling for die casting with conformal cooling channels

[5] B.Duleba, F. Greskovic - Conformal cooling for plastics injection moulding, Technical University of Kosice

[6] Wei Gao, Yunbo Zhang, Devarajan Ramanujan, Karthik Ramani, Yong Chen, Christopher B. Williams, Charlie C.L. Wang, Ying C. Shin, Song Zhang, Pablo D. Zavattieri, The status, challenges, and future of additive manufactoring engineering. 2015

[7] https://www.fabbaloo.com/blog/2016/11/16/variable-layer-slicing-for-the-ember-3d-printergood-idea-or-not

[8] https://www.totalmateria.com/page.aspx?ID=CheckArticle\&site=kts\&LN=ES\&NM=488 